\title{
1 The thermal structure of cratonic lithosphere from global Rayleigh wave attenuation
}

3 Colleen A. Daltona, Xueyang Baob, and Zhitu Ma

4

5 aDepartment of Earth, Environmental and Planetary Sciences, Brown University, 324 Brook

6 St., Box 1846, Providence, RI 02912, United States

8 bGraduate School of Oceanography, University of Rhode Island, 215 South Ferry Rd.,

$9 \quad$ Narragansett, RI 02882, United States

10

11 Corresponding author: Colleen A. Dalton, colleen_dalton@brown.edu

12 


\section{Abstract}

14 The resolution of and level of agreement between different attenuation models has

15 historically been limited by complexities associated with extracting attenuation from

16 seismic-wave amplitudes, which are also affected by the source, the receiver, and

17 propagation through velocity heterogeneities. For intermediate- and long-period Rayleigh

18 waves, removing the amplitude signal from focusing and defocusing effects is the greatest

19 challenge. In this paper, three independent data sets of fundamental-mode Rayleigh wave

20 amplitude are analyzed to investigate how three factors contribute to discrepancies

21 between the attenuation models: uncertainties in the amplitude measurements themselves,

22 variable path coverage, and the treatment of focusing effects. Regionalized pure-path and

23 fully two-dimensional attenuation models are derived and compared. The approach for

24 determining attenuation models from real data is guided by an analysis of amplitudes

25 measured from synthetic spectral-element waveforms, for which the input Earth model is

26 perfectly known. The results show that differences in the amplitude measurements

27 introduce only very minor differences between the attenuation models; path coverage and

28 the removal of focusing effects are more important. The pure-path attenuation values

29 exhibit a clear dependence on tectonic region at shorter periods that disappears at long

30 periods, in agreement with pure-path phase-velocity results obtained by inverting Rayleigh

31 wave phase delays. The 2-D attenuation maps are highly correlated with each other to

32 spherical-harmonic degree 16 and can resolve smaller features than the previous

33 generation of global attenuation models. Anomalously low attenuation is nearly perfectly

34 associated with continental cratons. Variations in lithospheric thickness are determined by

35 forward modeling the global attenuation variations as a thermal boundary layer of variable

36 thickness. Temperature profiles that satisfy the attenuation values systematically

37 overpredict and underpredict Rayleigh wave phase velocity in cratons at short and long 
38 periods, respectively. Introducing a low-velocity layer at depths 60-80 $\mathrm{km}$ and a high-

39 velocity layer that begins at $200 \mathrm{~km}$ can resolve the discrepancy. The former is consistent

40 with receiver-function detections of a mid-lithospheric discontinuity, and the latter may

41 correspond to the Lehmann discontinuity.

42

43 Keywords: seismic attenuation, surface waves, tomography, lithospheric thickness, mid-

44 lithospheric discontinuity, mantle temperature

45

46 


\section{1. Introduction}

48 Seismic-wave attenuation (1/Q) offers great potential for revealing the physical and

49 chemical state of the mantle, complementing the information provided by seismic velocity.

50 For example, coherent upwelling flow between the lower and upper mantle has been

51 inferred on the basis of agreement between the patterns of attenuation in the mantle

52 transition zone, low shear velocities in the lower mantle, and hotspot locations at the

53 surface (Romanowicz and Gung, 2002). Attenuation in the upper mantle can help to identify

54 the presence of water (Rychert et al., 2008) and melt (Abers et al., 2014). It can also be used

55 to place bounds on the range of mantle potential temperatures (Dalton et al., 2009) and to

56 account for anelastic effects on seismic velocity, yielding more accurate estimates of

57 temperature from wave speed (e.g., Goes and van der Lee, 2002).

58 However, challenges in isolating the signal of attenuation in seismic data have

59 historically hindered the development of attenuation models, limiting both the resolution of

60 the models and the level of agreement between different attenuation studies (see Fig. 17 of

61 Dalton et al., 2008). In addition to attenuation, surface-wave amplitudes are affected by

62 excitation at the earthquake source, local structure and the instrument response at the

63 receiver, and propagation effects such as focusing, defocusing, and scattering. These factors,

64 if not accounted for, can be erroneously mapped into attenuation, biasing the resulting

65 values (Selby and Woodhouse, 2000; Dalton and Ekström, 2006; Yang et al., 2007). It has

66 even been suggested that most of the observed seismic attenuation could be explained by

67 elastic heterogeneities rather than dissipative mechanisms (Ricard et al., 2014), although

68 wavefield simulations have shown that elastic scattering will enhance attenuation of

69 fundamental-mode Rayleigh waves by at most a few percent (Dalton et al., 2014; Meschede

70 and Romanowicz, 2015). 
Source and receiver effects on amplitudes can be reasonably well estimated as long

72 as each event is recorded by a large number of stations and each station records a large

73 number of earthquakes (Ekström et al., 2006; Ferreira and Woodhouse, 2006; Dalton et al.,

74 2014; Ma et al., 2016). Focusing effects, on the other hand, are controlled by gradients in

75 seismic velocity and therefore depend on both the characteristics of velocity heterogeneity

76 and the orientation of the propagation path relative to velocity heterogeneity. While full-

77 waveform inversions, which have begun to produce high-resolution regional models of

78 mantle attenuation (Zhu et al., 2013), can account for focusing effects in a self-consistent

79 way, all other attenuation studies require the use of approximate theory. The great-circle

80 ray approximation (GCRA; Woodhouse and Wong, 1986) treats the surface wave as a thin

81 ray confined to the great-circle path, exact ray theory (ERT; Woodhouse and Wong, 1986;

82 Wang and Dahlen, 1994; Larson et al., 1998) treats the surface wave as a thin ray that is

83 allowed to bend according to elastic structure, and finite-frequency theory (FFT; Zhou et al.,

842004 ) distributes the surface-wave sensitivity over a broad region surrounding the great-

85 circle path. Dalton et al. (2014) evaluated the validity of each theoretical treatment by

86 computing spectral-element synthetic seismograms using a 3-D velocity model and a 1-D

87 attenuation model. They also showed that while failure to remove focusing effects from

88 amplitudes introduced shorter-wavelength artifacts into attenuation models, the longer

89 wavelengths can be faithfully recovered, confirming the findings of earlier observational

90 studies (Romanowicz, 1995; Selby and Woodhouse, 2000).

91 Recently, three independent studies have produced global long-wavelength

92 Rayleigh wave attenuation maps that exhibit a high level of agreement (Dalton and Ekström,

93 2006; Ma et al., 2016; Bao et al., 2016). While all three studies account for source, receiver,

94 and focusing effects, they use different amplitude data sets and different approaches for the

95 removal of focusing effects. The attenuation maps are dominated by tectonic-scale features 
96 at short and intermediate periods, including high attenuation along mid-ocean ridges, low

97 attenuation beneath old seafloor, and low attenuation associated with stable continental

98 interiors. The correlation coefficients between each pair of 50-s maps are $>0.85$ at

99 spherical-harmonic degree 12; to provide some context for this value, Dalton and Ekström

100 (2006) report correlation coefficients between their results and the early studies of

101 Romanowicz (1995) and Selby and Woodhouse (2000) in the range 0.24-0.44.

102 This general consistency between the three independent sets of attenuation maps

103 represents significant progress in global attenuation imaging. In this paper we analyze the

104 three observed amplitude data sets and solve for Rayleigh wave attenuation with both

105 regionalized and generic 2-D parameterization schemes. By treating consistently all three

106 data sets we can assess the robustness of features in the models and identify the origin of

107 the differences between the maps. The synthetic amplitudes generated by Dalton et al.

108 (2014) guide this analysis by allowing an investigation into how erroneous features can be

109 introduced into attenuation maps as a result of unmodelled propagation effects.

110 In the new attenuation maps, which provide a higher resolution than the earlier

111 studies, there is an excellent correlation between areas of very low attenuation and

112 Precambrian crust. Although these same areas are also characterized by fast seismic

113 velocity, challenges associated with separating the competing effects of temperature and

114 composition on velocity have made it difficult to extract reliable cratonic geotherms from

115 velocity models (e.g., Pedersen et al., 2009; Lebedev et al., 2009; Hirsch et al, 2015).

116 Attenuation, on the other hand, is typically considered to be much less sensitive to

117 compositional variations and should be a more useful proxy for mantle temperature,

118 especially if temperatures are low enough to minimize anelastic effects related to melt and

119 volatiles. Here, we demonstrate that the temperature structures that are compatible with

120 the Rayleigh wave attenuation values agree with the constraints provided by xenolith 
121 thermobarometry and surface heat flow. These independent constraints on mantle

122 temperature make it possible to determine the effect of mantle composition on shear

123 velocity in cratonic lithosphere.

124

125 2. Rayleigh Wave Amplitudes and Focusing Effects

126 This study utilizes four different global data sets of fundamental-mode Rayleigh

127 wave amplitudes (Table 1); three of these were measured from observed waveforms and

128 one was measured from synthetic waveforms. The amplitudes used by Dalton et al. (2008)

129 (hereinafter DED08) were measured using the algorithm of Ekström et al. (1997) applied to

130 earthquakes with $M_{W}>6.0$ that occurred during 1993-2005. The amplitude data used by Ma

131 et al. (2016) (hereinafter MMM16) were measured by a cluster analysis technique applied

132 to earthquakes with $\mathrm{M}_{\mathrm{W}}>5.0$ that occurred during 1991-2007. The amplitude data used by

133 Bao et al. (2016) (hereinafter BDR16) were measured using the mode-branch stripping

134 technique of van Heijst and Woodhouse (1997) applied to earthquakes that occurred during

135 1991-2007. All three observed amplitude data sets account for the effects of the source,

136 geometrical spreading, attenuation, and the receiver in a 1-D Earth using PREM

137 (Dziewonski and Anderson, 1981) and the Global CMT solutions (Dziewonski et al., 1981;

138 Ekström et al., 2012); the DED08 and BDR16 data were measured with respect to reference

139 waveforms, whereas MMM16 computed and applied the corrections to their measurements.

140 We pre-calculate and remove focusing effects with the velocity models used in the original

141 studies for BDR16 and MMM16 and with the GDM52 maps of Ekström (2011) expanded in

142 spherical harmonics to degree 20 for DED08 (Table 1). Finally, we remove paths for which

143 the earthquake is not recorded at $>30$ receivers or the station does not record $>30$

144 earthquakes. Overall the three observed amplitude data sets are in strong agreement (Fig.

145 S1). For source-receiver paths held in common between pairs of data sets, the variance 
146 reductions are $82-93 \%$ and the correlation coefficients range between 0.92 and 0.96 . The

147 fourth set of amplitude data was measured from spectral-element synthetic seismograms

148 that were generated using the software package SPECFEM3D_GLOBE (Komatitsch and

149 Tromp, 2002a,b). The wavefield simulations, described in detail by Dalton et al. (2014),

150 used a global 3-D elastic Earth model, a 1-D attenuation model, and 42 globally distributed

151 earthquakes. Focusing has been pre-calculated using ERT, GCRA, and FFT applied to phase-

152 velocity maps computed from the 3-D model used for the simulation.

153 Fig. 1 compares predictions of the focusing amplitude for 50-s Rayleigh waves. The

154 outliers tend to dominate the scatter plot and obscure the fact that for the majority of paths

155 the two sets of predictions are close to the 1:1 line. The comparisons in Fig. 1 also show that

156 the relationship between the GCRA and FFT predictions is nearly linear: both approaches

157 contain the assumption of propagation along the great circle and a focusing prediction that

158 varies linearly with the phase-velocity perturbation. Furthermore, the relationships

159 between the GCRA/ERT and FFT/ERT predictions are nonlinear due to the log-normal

160 distribution of ERT log-amplitudes versus the normal distribution of GCRA and FFT

161 predictions (Larson et al., 1998). The validity of each theoretical treatment for focusing

162 effects is assessed through comparison with the amplitudes measured from the spectral-

163 element synthetic seismograms, from which source and receiver effects have been removed

164 so that the remaining signal can be considered to have originated during propagation (Fig.

165 S2). The ERT predictions provide the best fit to the 50-s measurements (Dalton et al., 2014)

166 and reduce the variance of the measurements by 15\%; GCRA and FFT do not provide

167 positive variance reduction at 50 s. For 75-s and 125-s Rayleigh waves, only FFT provides

168 positive variance reduction: $14 \%$ at $75 \mathrm{~s}$ and $27 \%$ at $125 \mathrm{~s}$, demonstrating that the validity

169 of the theoretical treatments depends on period.

170 

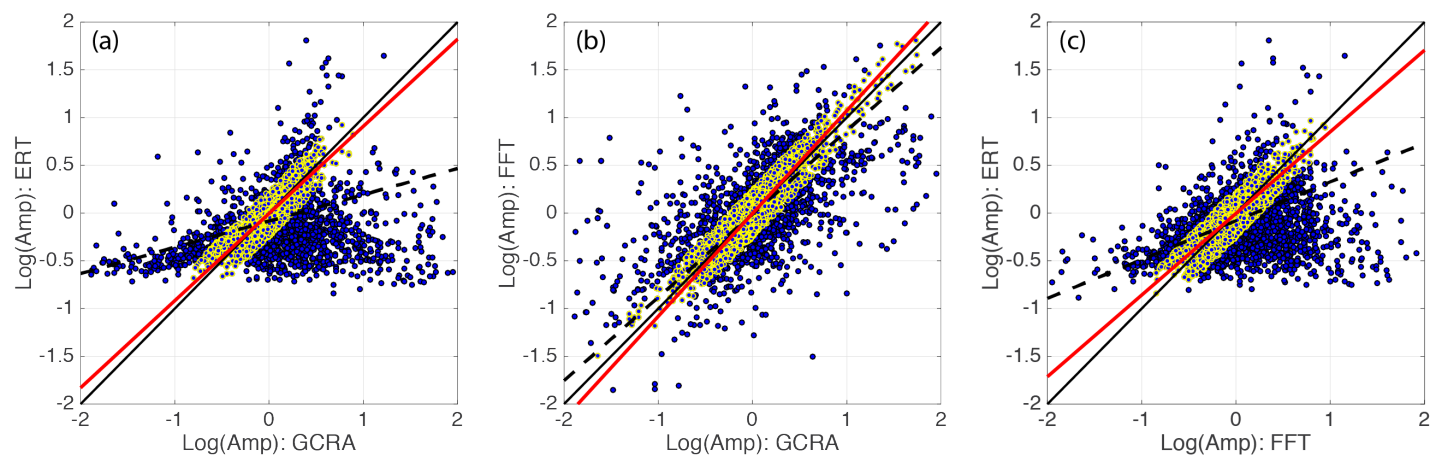

174 Figure 1. Comparison of focusing-predicted amplitudes for 50-s Rayleigh waves using a degree-20 phase-velocity map and three approximate theories. Blue circles show all 4,749 paths. Yellow circles show $80 \%$ of paths with the smallest absolute difference between the two predictions. Red and dashed black lines are the best-fitting lines using orthogonal regression applied to the $80 \%$ subset of points and all points, respectively.

181 inverting amplitude data is presented in Fig. 2. A synthetic amplitude data set that is sensitive to both attenuation and focusing effects is generated by multiplying the spectral-

183 element amplitudes (Fig. S2) by amplitudes computed by integrating along great-circle

184 paths through an input attenuation map that was created by scaling the 50 -s phase-velocity 185 map by a factor that produces attenuation variations with a similar magnitude to those 186 observed for the real Earth. This synthetic data set is then inverted for attenuation structure 187 with four different treatments of focusing effects: none, GCRA, ERT, and FFT. Figs. 2c,d 188 demonstrate that (i) the short-wavelength attenuation features are most strongly impacted 189 by the treatment of focusing effects, and (ii) using ERT at $50 \mathrm{~s}$ and FFT at $125 \mathrm{~s}$ produces an 190 output attenuation map that is most similar to the input map. Importantly, all three 191 theoretical treatments yield output maps that are greatly improved relative to the case 192 where focusing effects are not removed. 


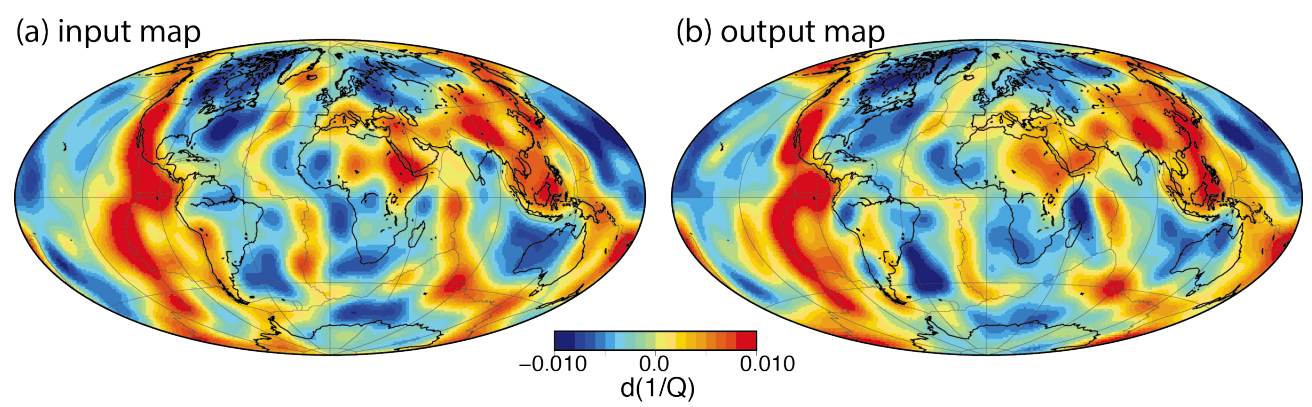

(c) $50 \mathrm{~s}$

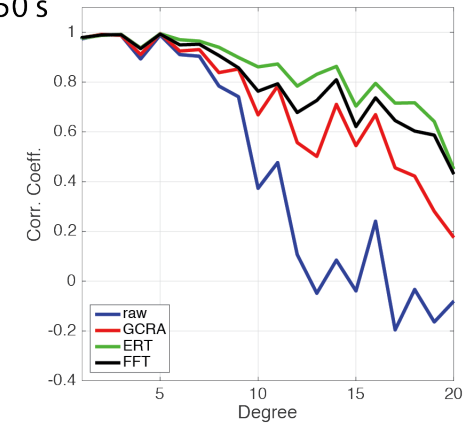

(d) $125 \mathrm{~s}$

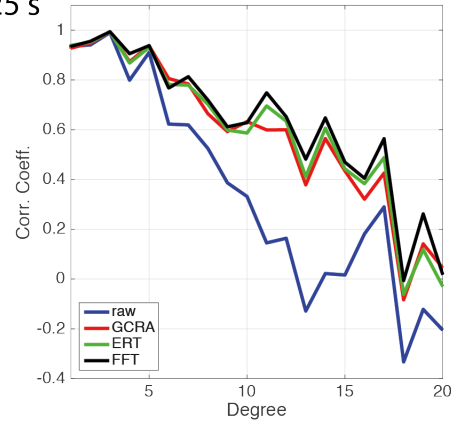

195 Figure 2. (a) Input attenuation map, created by scaling a 50-s phase-velocity map. (b) Output attenuation map obtained by inverting an amplitude data set that has sensitivity to lateral attenuation variations and unmodelled path effects such as focusing. Focusing effects predicted with ERT have been removed from the amplitude data. Both maps are expanded in spherical harmonics to degree 20. (c) Correlation coefficient at each degree between the input attenuation map and four output maps. Blue: focusing effects not removed from amplitude data. Red, green, and black show focusing effects removed with GCRA, ERT, and FFT, respectively. (d) Results for the same experiment performed for 125-s Rayleigh waves.

\section{Pure-Path Regionalized Inversions}

As an initial exploration into the constraints on lateral attenuation structure that are

206 suggested by the three observed data sets of Rayleigh wave amplitude, we use the amplitude measurements to estimate attenuation anomalies in the six tectonic regions identified by Jordan (1981) in the Global Tectonic Regionalization (GTR1) scheme. GTR1 contains three oceanic regions, distinguished by seafloor age: young (A; 0-25 Myr),

210 intermediate age (B; 25-100 Myr), and old (C; >100 Myr). The continents are divided into

211 three regions on the basis of their tectonic behavior during the Phanerozoic: platforms 
212 overlain by Phanerozoic cover (P), Phanerozoic deformation zones (Q), and exposed

213 Archean and Proterozoic shields and platforms (S). We refer to regions $\mathrm{P}$ and S together as

214 stable continents or cratons.

215 Each amplitude measurement $A_{i j}(\omega)$, corresponding to earthquake source $i$ and 216 seismic receiver $j$, is considered to depend on four factors

$218 A_{i j}(\omega)=A_{i}^{S}(\omega) A_{j}^{R}(\omega) A_{i j}^{F}(\omega) A_{i j}^{Q}(\omega)$,

220 where $\omega$ indicates the angular frequency and the superscripts $S, R, F$, and $Q$ refer to source,

221 receiver, focusing/defocusing, and attenuation effects, respectively. The amplitude data are

222 sensitive to perturbations in Rayleigh wave attenuation $\delta\left(Q^{-1}\right)$ away from the value

223 predicted by PREM integrated along the ray path $d s(\theta, \phi)$

$A^{Q}(\omega)=\exp \left[\frac{-\omega}{2 U(\omega)} \int \delta\left(Q^{-1}\right)(\omega, \theta, \phi) d s(\theta, \phi)\right]$

227 where $U(\omega)$ is group velocity, $\theta$ is latitude, and $\phi$ is longitude. Since the attenuation effect, 228 unlike the focusing effect, accumulates linearly, using the great-circle path instead of exact 229 ray theory or finite-frequency theory is appropriate for the relatively long-wavelength 230 variations of interest here (e.g., Wang and Dahlen, 1994; 1995). The pure-path regionalized 231 inversion determines, in addition to a frequency-dependent attenuation anomaly $232\left[\delta\left(Q^{-1}\right)\right]_{k}(\omega)$ in the $k$ th tectonic region, a scalar correction for each source and each 233 receiver:

$$
\frac{-2 U}{\omega} \ln \left[A_{i j}(\omega) / A_{i j}^{F}(\omega)\right]=\frac{-2 U}{\omega}\left\{\ln \left[A_{i}^{S}(\omega)\right]+\ln \left[A_{j}^{R}(\omega)\right]\right\}+\sum_{k=1}^{6} X_{i j}^{k}\left[\delta\left(Q^{-1}\right)\right]_{k}(\omega)
$$


236 where $X_{i j}^{k}$ indicates the path length through the $k$ th tectonic region. Focusing effects, if 237 accounted for, are pre-calculated and removed from each datum prior to inversion. The 238 unknown parameters are solved for with least-squares minimization using Cholesky 239 factorization; the only a priori constraint is requirement that the $\ln \left[A_{j}^{R}\right]$ terms sum to zero.

240 Attenuation anomalies obtained using the three different amplitude data sets 241 (uncorrected for focusing effects) are largely consistent (Fig. 3a), although the three sets of 242 values are offset slightly from each other. The offset can be attributed almost entirely to 243 path coverage; when the inversion is repeated using only the paths shared in common by all 244 three data sets the offset disappears. The pure-path attenuation results obtained from the 245 SPECFEM amplitudes, for which the input attenuation model was uniform, show a very 246 different pattern.

247 When focusing effects are removed from the observed amplitude data, the result is 248 to increase the global range of estimated attenuation values (Fig. 3b) by enhancing 249 attenuation in young oceans (A) and active continents (Q) and reducing attenuation in old 250 oceans (C) and stable continents (regions $\mathrm{P}$ and S). While the sign of this adjustment is 251 consistent for almost all types of focusing predictions, the magnitude of the correction 252 depends on the approximate theory and phase-velocity map used. Removing focusing 253 effects from the SPECFEM amplitudes adjusts the attenuation values in the same direction 254 as for the observed data, which has the effect of reducing the global range by nearly a factor 255 of two. The range of $1 / Q$ values before and after the removal of focusing effects from the 256 SPECFEM amplitudes is 0.0069-0.0112 and 0.0070-0.0094, respectively; the input Rayleigh 257 wave attenuation at $50 \mathrm{~s}$ was 0.00866 . The difference between the input and output 258 attenuation values (with focusing effects removed) corresponds to an error of $6-10 \%$ for 259 regions $A, B, C, P$, and $\mathrm{Q}$ and $18 \%$ for region S; in Section 5 these errors are assumed to 
260 apply at all periods and used to constrain mantle thermal structure. The adjustment to a

261 smaller global range after focusing effects are removed from the SPECFEM data is of the

262 opposite sense from the adjustment to a larger global range observed with real data and is

263 consistent with the uniform attenuation structure that was prescribed for the SPECFEM

264 simulations. The ability of the pure-path inversion to recover the input anelastic structure

265 reasonably well suggests that the attenuation anomalies obtained from the real data

266 accurately represent the anelastic properties of the Earth's interior.

267 Fig. 3c shows the GTR1 attenuation anomalies obtained with the MMM16 268 amplitudes corrected for focusing effects using FFT (Table 2); results for BDR16 at 50 and $269100 \mathrm{~s}$ and DED08 at 50, 75, 100, and $125 \mathrm{~s}$ are shown for comparison. Fig. S3a summarizes

270 the variance reduction relative to that provided by only the source and receiver factors. The 271 pure-path results provide the best fit to the data at short periods $(\sim 14 \%)$ and almost no 272 variance reduction at the longest periods $(\sim 1.4 \%)$. Fig. S4 illustrates the depth sensitivity of 273 Rayleigh waves of different periods to the Earth's intrinsic shear and bulk attenuation.

274 Fig. 3d shows phase-velocity perturbations for the GTR1 regions, obtained by 275 inverting the Rayleigh wave time delays $\delta t_{i j}(\omega)$ measured by Ma et al. (2014) for pure-path 276 phase-slowness anomalies $\delta p_{k}$ in each GTR1 region

$278 \delta t_{i j}(\omega)=\sum_{k=1}^{6} X_{i j}^{k} \delta p_{k}(\omega)$.

280 Results obtained from inverting the eigenfrequency perturbations of Ritsema et al. (2011) 281 are also shown, and variance reduction is plotted in Fig. S3b.

282 The attenuation and phase-velocity anomalies are anti-correlated with each other at 283 short and intermediate periods. Excluding temporarily the 40-s results, the global range of 284 attenuation and phase velocity is largest at 50 and $66 \mathrm{~s}$ and minimum at $200 \mathrm{~s}$, although the 
285 stable continents $(\mathrm{P}, \mathrm{S})$ are characterized by low attenuation and high velocity even at $200 \mathrm{~s}$.

286 The three oceanic regions $(A, B, C)$ show a clear dependence on seafloor age, with the highest

287 attenuation and slowest velocity at young ages. Stable continents reach their minimum

288 attenuation anomaly and maximum velocity anomaly at $66 \mathrm{~s}$. The 40 -s results are consistent

289 with a stronger influence of the crust on phase velocity than on attenuation. Fig. $3 \mathrm{~d}$ shows

290 that relative to PREM the three oceanic regions are characterized by a slight reduction in

291 the velocity anomaly between 40 and $50 \mathrm{~s}$ whereas the three continental regions exhibit a

292 velocity increase, which is large for the stable continents. The attenuation curves do not

293 show such an obvious distinction between oceanic and continental regions in this period

294 range. We also note that while intermediate-age oceans (B) and active continents (Q)

295 exhibit very similar attenuation values at all periods, phase velocity for Q is much lower

296 than for B at periods < 100 s. These differences between the oceanic and continental

297 observations and between the phase-velocity and attenuation curves can be explained if the

298 well-known velocity increase with depth that occurs at the continental Moho is not

299 accompanied by a corresponding reduction in attenuation. Most mantle attenuation studies

300 contain the assumption of a low-absorption crust (e.g., Durek and Ekström, 1996), which

301 the results in Fig. 3c-d support.

302 The values of attenuation and phase velocity obtained using the GTR1

303 regionalization can be considered representative of the seismic properties of the crust and

304 shallow mantle. This conclusion is evident from the fact that these values provide higher

305 variance reduction at shorter periods and is to be expected given that the GTR1

306 regionalization scheme is guided by surficial properties such as seafloor age and tectonic

307 behavior. The tendency of the values to converge at long periods reflects weakening

308 correspondence between surface-tectonic features and the patterns of elastic and anelastic 
309 heterogeneity at greater mantle depths. In Section 5, we explore the upper-mantle 310 temperature variations that are suggested by both sets of values.

311

312

313

314

315

316

317

318

319 

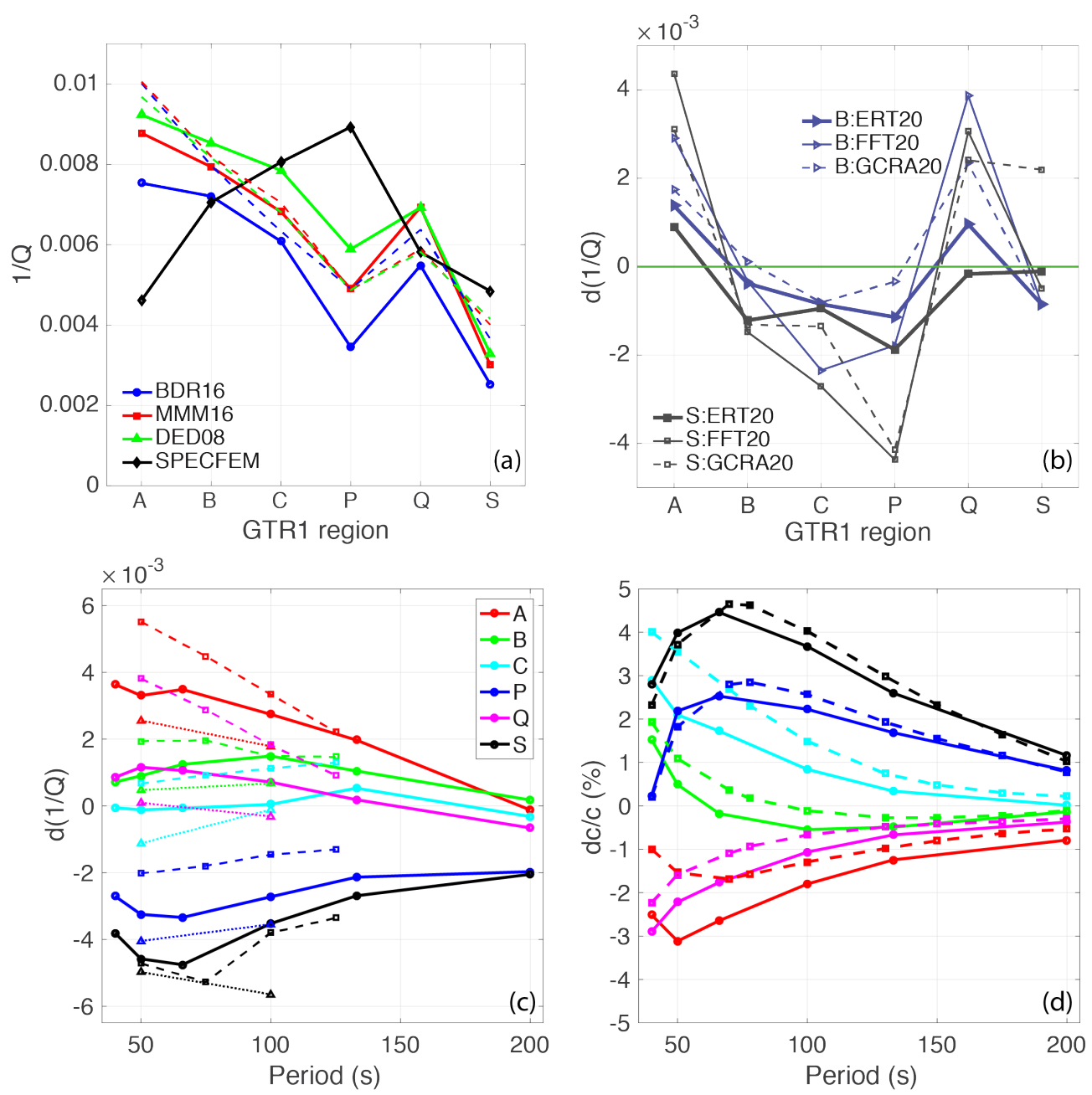

321 Figure 3. Rayleigh wave attenuation and phase velocity determined for the six tectonic regions of GTR1 (Jordan, 1981). All attenuation inversions also solve for source and receiver terms. (a) 50-s attenuation (1/Q) determined from the three amplitude data sets, with no correction for focusing effects. Solid lines: all available data used. Dashed lines: only paths shared by all three data sets used. Black curve shows the attenuation determined from the synthetic SPECFEM amplitudes. (b) Effect of accounting for focusing effects on the regional attenuation values. Separate results are shown for focusing effects predicted with ERT, FFT, and GCRA. Blue=BDR16 amplitudes. Grey=SPECFEM amplitudes. Attenuation anomalies are plotted as absolute deviations from the values in (a). (c) Regional attenuation anomalies, expressed as absolute perturbations to the PREM $1 / Q$ values. See Fig. 6c for absolute attenuation values and error bars. Solid: MMM16 amplitudes with focusing effects removed using FFT. Dashed: DED08 amplitudes with focusing effects removed using GCRA. Dotted: BDR16 amplitudes with focusing effects removed using ERT. (d) Regional phase-velocity anomalies, expressed relative to PREM phase velocities. Solid: the travel-time data set of Ma et al. (2014). Dashed: the eigenfrequency-perturbation data set of Ritsema et al. (2011). 
The three sets of observed Rayleigh wave amplitudes $A_{i j}$ are inverted for attenuation

338 variations expanded in spherical harmonics to degree 16 and correction factors for each

339 source $i$ and each receiver $j$ :

$\frac{-2 U}{\omega X_{i j}} \ln \left[A_{i j}(\omega) / A_{i j}^{F}(\omega)\right]=\frac{-2 U}{\omega X_{i j}}\left\{\ln \left[A_{i}^{S}(\omega)\right]+\ln \left[A_{j}^{R}(\omega)\right]\right\}+\sum_{l=0}^{L} \sum_{m=-l}^{l} q_{l m} \overline{Y_{l m}}$.

343 In this equation $X_{i j}$ is the path length, $q_{I m}$ are the spherical-harmonic coefficients to be 344 determined, $\overline{Y_{l m}}$ is the path average of the spherical-harmonic function, and $L$ is the 345 maximum degree of the spherical-harmonic expansion. In each case, focusing effects can be 346 pre-calculated and removed from the amplitudes prior to inversion. A smoothness 347 constraint is applied by minimizing the squared gradient of the attenuation perturbation, as 348 described by Dalton and Ekström (2006), using the same smoothness coefficient for all 349 scenarios.

350 Fig. 4 shows the attenuation maps at $50 \mathrm{~s}$ and $100 \mathrm{~s}$; variance reduction is 351 summarized in Fig. S3a. These degree-16 maps are able to resolve specific features that 352 were not present in previous global attenuation studies. Most notably, low attenuation is 353 nearly perfectly associated with continental cratons. Fig. 5a shows the crustal types in 354 CRUST1.0 (Laske et al., 2013) grouped by age. Very low attenuation beneath specific 355 continental cratons can be seen in this comparison, for example the Amazonia craton in 356 South America, the West Africa, Congo, and Kaapvaal cratons in Africa, the Baltic Shield and 357 Russian Platform in western Eurasia, and the Siberian craton in eastern Eurasia. The 358 attenuation models contain low attenuation in western Australia, although it appears to 359 align more closely with the Pilbara craton and Proterozoic rocks in the northwest than it 360 does with the Archean Yilgarn craton in the southwest. We also note that all three 
361 attenuation maps contain a zone of very low attenuation just immediately northeast of the

362 Caspian Sea in an area that is characterized as Phanerozoic in CRUST1.0.

363 In the 50-s maps, high attenuation is found beneath tectonically active western

364 North America, eastern Africa, the Lau back-arc spreading center, and extending inland

365 from the Nigerian coast, roughly aligned with the Cameroon Volcanic Line. Attenuation also

366 exhibits a clear dependence on seafloor age, with higher attenuation at younger ages, as

367 expected for a lithosphere that cools and thickens over time. This seafloor-age relationship

368 is characterized by greater scatter than is the case for the age dependence of phase velocity,

369 and the correlation coefficient between the 50-s MMM16 attenuation and GDM52 phase-

370 velocity maps, which is -0.58 globally, is weaker in oceanic areas and stronger in continental

371 areas: -0.49 for the $44 \%$ of pixels with crustal thickness $5-9 \mathrm{~km},-0.67$ for the $6 \%$ of pixels

372 with thickness $28-32 \mathrm{~km}$, and -0.75 for the $11 \%$ of pixels with crustal thickness $37-41 \mathrm{~km}$.

373 The weaker oceanic age-dependence for the attenuation maps could originate from

374 imperfect corrections for focusing effects or it could also reflect differences in the sensitivity

375 of attenuation and velocity to factors like melt and volatiles.

376 

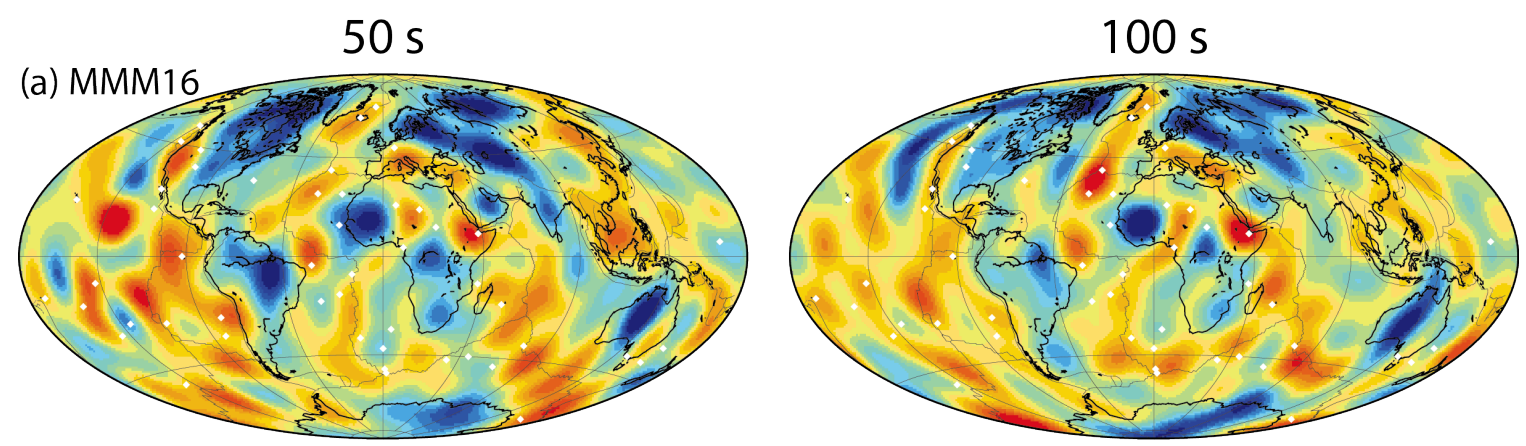

(b) BDR16
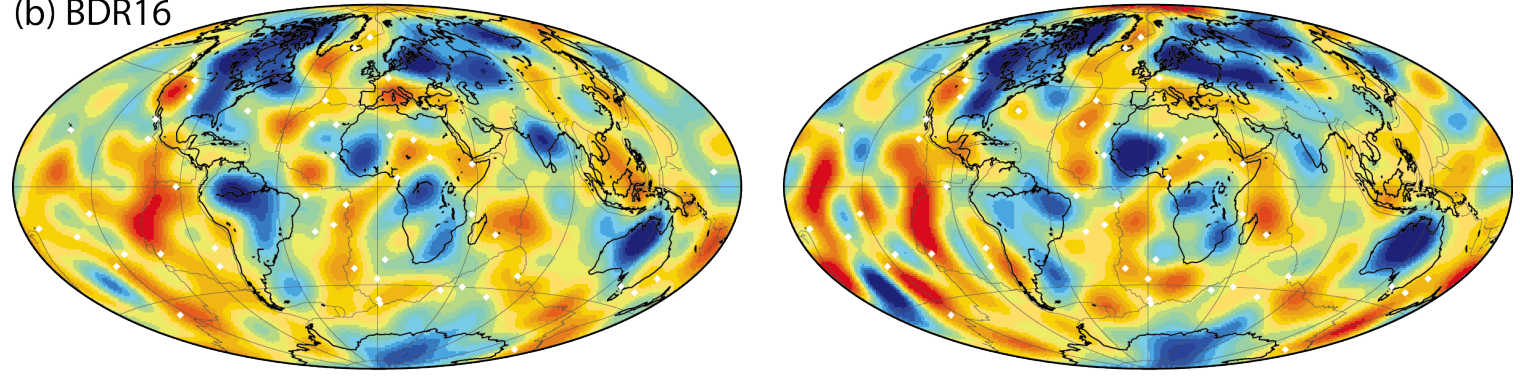

(c) DED08

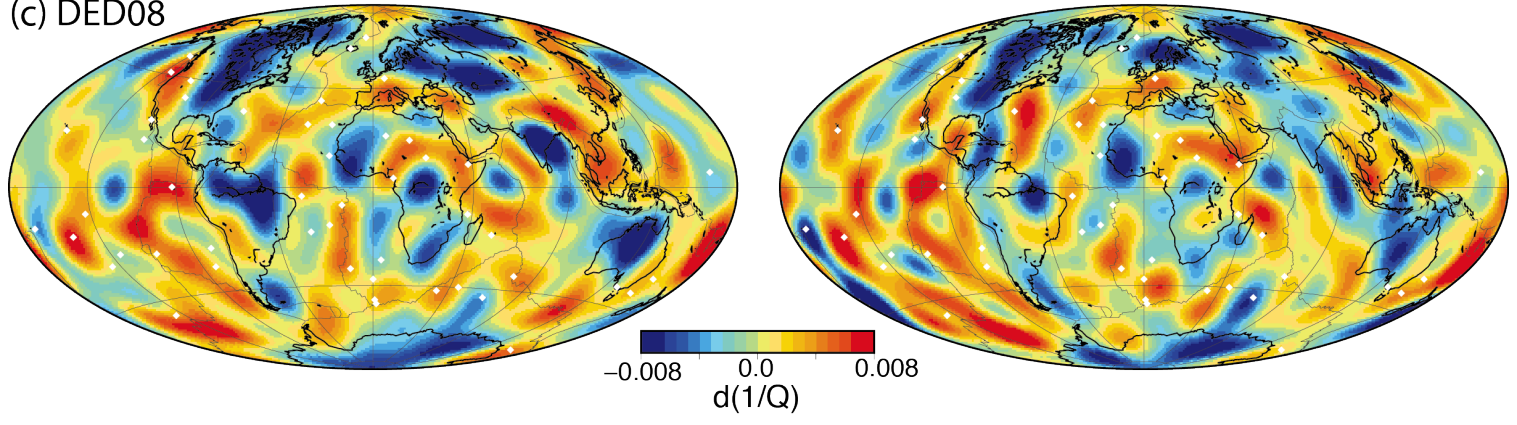

378 Figure 4. Degree-16 attenuation maps for 50-s and 100-s Rayleigh waves. These maps are

379 determined using all possible paths for each data set. (a) MMM16 amplitudes, corrected for focusing

380 effects using FFT. (b) BDR16 amplitudes, corrected for focusing effects using ERT at $50 \mathrm{~s}$ and FFT at

381100 s. (c) DED08 amplitudes, corrected for focusing effects using GCRA. White diamonds show

382 hotspot locations. The color scale shows absolute deviations in attenuation (1/Q) away from the

383 attenuation values predicted by PREM: 0.00635 at $50 \mathrm{~s}$ and 0.00846 at $100 \mathrm{~s}$.

The correlation coefficient between each pair of maps in Fig. 4 ranges between 0.77

386 and 0.80 at $50 \mathrm{~s}$ and 0.51 and 0.83 at $100 \mathrm{~s}$ (Fig. 5b). The lack of perfect correlation results

387 from a combination of two factors: the different path coverage of the three data sets and the

388 different corrections for focusing effects. When identical path coverage is used and focusing

389 effects are not removed, the maps are nearly identical. This result demonstrates that 
390 differences in the algorithms that measure the Rayleigh wave amplitudes have a negligible

391 effect on the retrieved attenuation structure. Removing focusing effects from the paths held

392 in common between the data sets reduces the correlation, as expected because focusing

393 effects are treated slightly differently in the three cases. Fig. S5 illustrates how the use of

394 different theories applied to a single phase-velocity map and data set influences the

395 attenuation structure. When the same theory and phase-velocity map are used to predict

396 focusing effects for all three data sets (i.e., focusing effects are treated consistently in the

397 three cases), the correlation is stronger than when focusing effects are not removed (Fig.

398 S6). Using all available paths instead of only the common paths changes the agreement

399 between pairs of models in two ways (Fig. 5b). One, when focusing effects are not removed

400 the correlation is weakened relative to when only common paths are used. Two, the

401 correlation between maps with focusing effects removed is stronger than when focusing

402 effects are not removed; using the same theory and phase-velocity map to predict focusing

403 effects for all three data sets further strengthens this correlation (Fig. S6).

404 The analysis described in the previous paragraph makes clear that not removing

405 focusing effects introduces artifacts into the maps, and removing focusing effects eliminates

406 many of these artifacts. When only paths held in common are used, the different focusing

407 corrections applied to each data set make the data sets less similar to each other and, as a

408 result, the attenuation maps are less similar. When all paths are used, the artifacts, since

409 they are not true features of the Earth, will depend on which paths are included; the

410 attenuation maps without focusing effects removed show considerable disagreement.

411 Removing focusing effects results in attenuation maps that are more representative of the

412 Earth's true anelastic structure and thus more similar to each other. Therefore, consistent

413 with the experiment performed on the SPECFEM amplitudes (Fig. 2), any of the three

414 approaches for removing focusing effects improves the recovery of the input model relative 
415 to not removing focusing effects at all. At $100 \mathrm{~s}$ the effects of path coverage and removal of

416 focusing are similar for the BDR16 and MMM16 comparison. The comparisons that utilize

417 the DED08 model indicate that removal of focusing effects results in a slightly weaker

418 correlation, perhaps because GCRA is especially poor at predicting focusing effects at longer

419 periods (Fig. S2c).

420

421

(a) crust classification

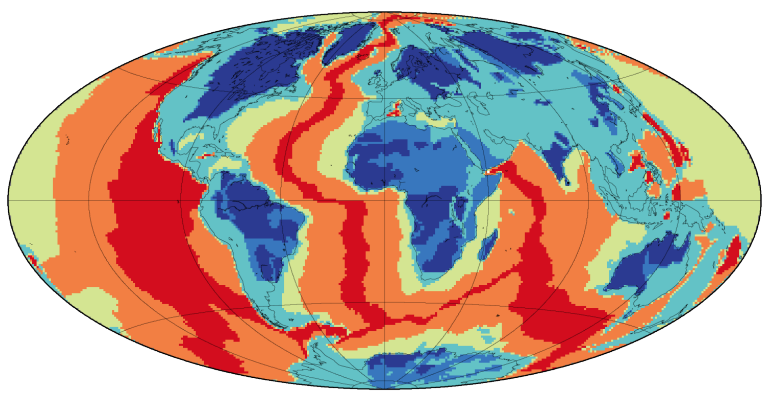

422

423

424

425

426

427

428

429

430

431

432

433

434

435

436 Numbers of paths in common is given in parentheses.

\section{Inferring Upper-Mantle Temperatures}

\subsection{Constructing Geotherms}
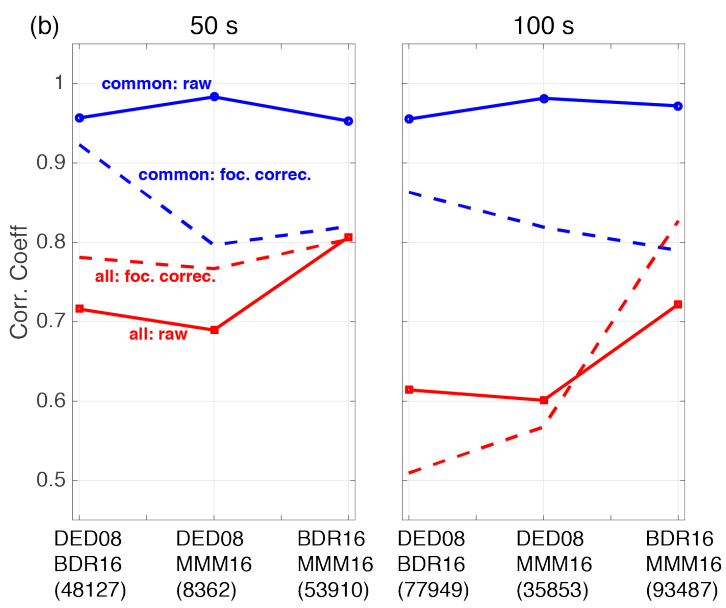

Figure 5. (a) Classification of crust according to CRUST1.0 (Laske et al., 2013). Dark, intermediate, and light blues indicate continental crust with early Proterozoic/Archean, mid-late Proterozoic, and younger ages, respectively. Seafloor is classified on the basis of age: 0-25 Myr, 25-100 Myr, and > 100 Myr according to Müller et al. (2008). (b) Correlation coefficient between each pair of degree-16 maps. Red curves correspond to maps determined with all possible paths for each data set; blue curves correspond to maps determined with identical path coverage. Solid and dashed lines correspond to maps determined from the raw and focusing-corrected amplitudes, respectively.

The single largest factor contributing to the global attenuation values in the upper mantle is temperature; it is well established that temperature variations are large (e.g., Goes et al., 2000; Artemieva, 2009) and that attenuation is strongly controlled by temperature 
437 (e.g., Jackson and Faul, 2010; McCarthy et al., 2011). Although attenuation can also be

438 enhanced by the presence of melt (Jackson et al., 2004; McCarthy and Takei, 2011) and

439 possibly water (e.g., Karato, 2003), we focus our interpretation below on stable continental

440 areas where these factors likely contribute little to the observed attenuation. It is not

441 straightforward to interpret the Rayleigh wave attenuation values in Figs. 3-4 in terms of

442 temperature variations at a single depth, since they are a depth-integrated quantity. Rather,

443 we investigate how well the attenuation variations can be explained by a simple thermal

444 structure: a thermal boundary layer (TBL) that joins the mantle adiabat at some depth.

445 Temperature profiles are constructed by specifying the mantle adiabat, defined by a

446 mantle potential temperature $\left(T_{P}\right)$ and a temperature gradient with depth, and the depth at

447 which the TBL intersects the adiabat. We consider 33 different adiabatic profiles, with 11

448 values of $T_{P}\left(1100^{\circ} \mathrm{C}-1600^{\circ} \mathrm{C}\right)$ spaced every $50^{\circ} \mathrm{C}$ and three values of the adiabatic

449 temperature gradient $d T_{a} / d z\left(0.25^{\circ} \mathrm{C} / \mathrm{km}, 0.40^{\circ} \mathrm{C} / \mathrm{km}, 0.55^{\circ} \mathrm{C} / \mathrm{km}\right)$. We consider 80 values

450 for the intersection depth spaced every $5 \mathrm{~km}$ between $5 \mathrm{~km}$ and $400 \mathrm{~km}$. The result is 2,640

451 different temperature profiles from the surface to $400-\mathrm{km}$ depth. The advantage of this

452 approach is that it is straightforward to map global variations in TBL thickness. Fig. S7

453 shows that our approach works particularly well in settings where the uppermost mantle is

454 generally cold. Relative to our temperature profiles, realistic cratonic geotherms that

455 incorporate radiogenic heat production in the crust and mantle (e.g., Rudnick et al., 1998)

456 have slightly higher temperatures at depths $<50 \mathrm{~km}$. However, since attenuation is very low

457 at these temperatures, the temperature differences produce only minor differences in the

458 predicted Rayleigh wave attenuation (Figs. S7a,b). Under hotter conditions, larger

459 differences in Rayleigh wave attenuation are found (Figs. S7c,d) and suggest that our

460 approach likely overestimates TBL thickness under hot conditions. 
462 parameterization of Jackson and Faul (2010), which is derived from torsional forced-

463 oscillation experiments performed on dry, melt-free forsterite-90 olivine. In order to

464 implement the frequency-dependent shear attenuation and seismic velocity inherent to that

465 parameterization, we take advantage of the fact that Rayleigh waves of different periods

466 sample different depths (Fig. S4) and assign a unique period at each depth according to:

467 period $(\mathrm{s})=\operatorname{depth}(\mathrm{m}) / 1400$ (Forsyth, 1992). We test two values of grain size $d(1 \mathrm{~mm}, 10$

$468 \mathrm{~mm}$ ). At depths $>400 \mathrm{~km}$ PREM (Dziewonski and Anderson, 1981) is used. Three separate

469 crustal structures are implemented; they were selected by identifying, for each of the six

470 GTR1 regions, what is the most common crustal type in CRUST1.0 (Laske et al., 2013). All

471 crustal parameters, including density and wave speed, are taken from CRUST1.0, and shear

472 attenuation is fixed at 1/300 throughout the crust (e.g., Durek and Ekström, 1996). For

473 comparison with oceanic regions, the shallow structure consists of $4.77 \mathrm{~km}$ of water, 0.50

$474 \mathrm{~km}$ of sediment, and $7.00 \mathrm{~km}$ of crystalline crust. For comparison with orogenic/magmatic

475 continents (Q) the crystalline crust is $30.0 \mathrm{~km}$ thick, and for comparison with the stable

476 continents $(\mathrm{P}, \mathrm{S})$ the crystalline crust is $39.0 \mathrm{~km}$ thick. Each crustal structure is placed on top

477 of each 1-D mantle seismic model, resulting in 23,760 1-D Earth models. 

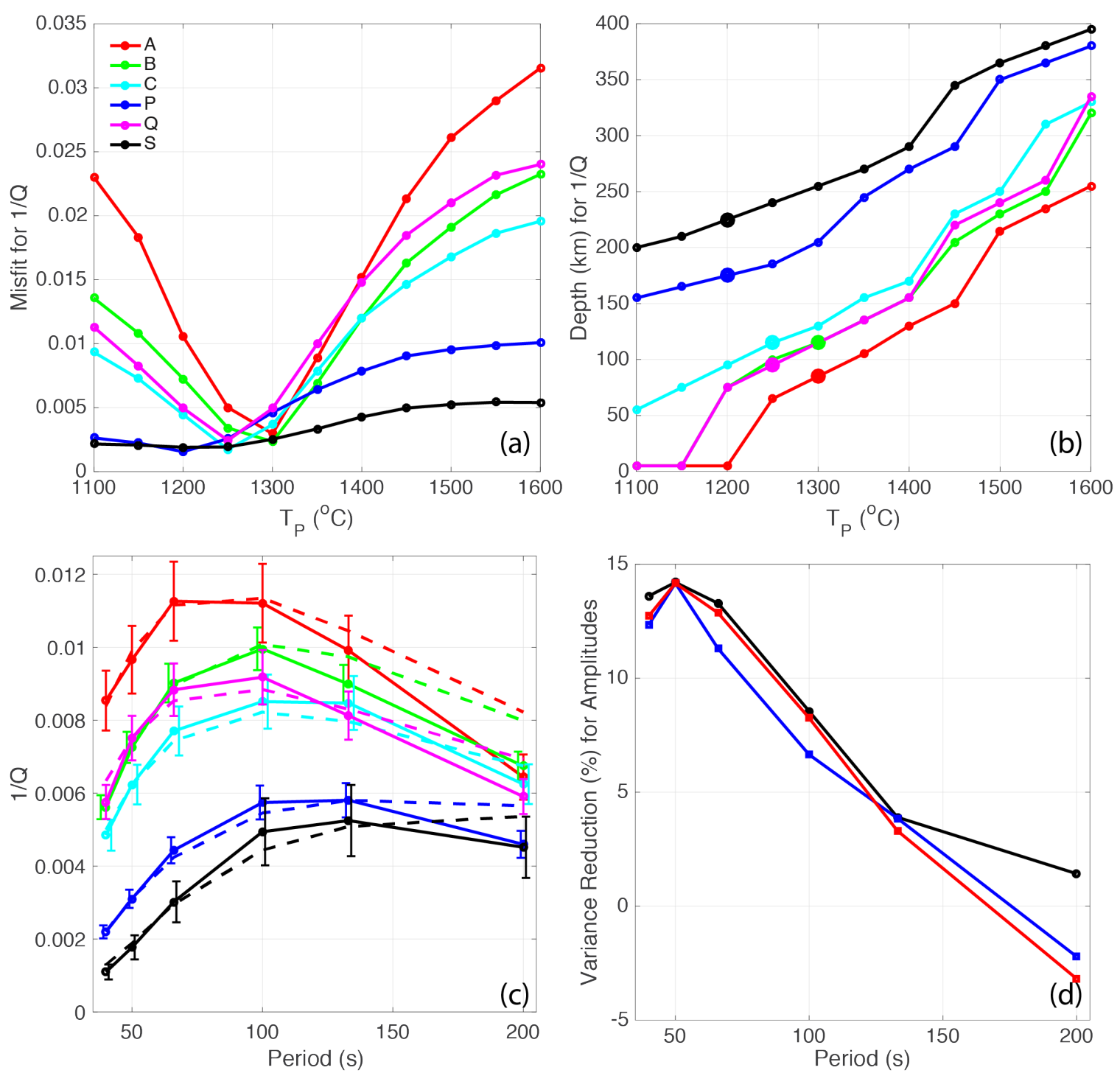

479 Figure 6. (a) Misfit for the GTR1 attenuation values as a function of $T_{P}$; here, $d=1 \mathrm{~mm}$ and

$480 d T_{a} / d z=0.40^{\circ} \mathrm{C} / \mathrm{km}$. (b) Best-fitting intersection depth for the GTR1 attenuation values as a function

481 of $T_{P}$. Large circles indicate the $T_{P}$ value at which misfit is minimized. (c) Comparison of observed

482 (solid) and predicted (dashed) attenuation; for each GTR1 region the best-fitting combination of $T_{P}$

483 and intersection depth is used for the predictions. The error-bar length is estimated from the relative

484 difference in the input and output attenuation values determined for each region using the 50-s

485 SPECFEM amplitudes (see Fig. 3b and Section 3). (d) Variance reduction for the MMM16 amplitude

486 data set. Variance reduction also includes source and receiver terms obtained from the GTR1

487 inversion and is expressed relative to the variance reduction provided by only the source and

488 receiver terms. Black: GTR1 attenuation values. Red: TBL models with $d=1 \mathrm{~mm}$. Blue: TBL models

489 with $d=10 \mathrm{~mm}$. 


\subsection{Determining TBL Thickness from Attenuation}

For each TBL model, Rayleigh wave attenuation at periods of 40, 50, 66, 100, 133,

493 and $200 \mathrm{~s}$ is predicted using Mineos and compared to the observed GTR1 values. Misfit is

494 calculated for each model as the sum over all periods of the absolute value of the difference

495 between observed and predicted attenuation. Fig. 6a summarizes the minimum misfit

496 between observed and predicted attenuation at each $T_{P}$ value for $d=1 \mathrm{~mm}$ and

$497 d T_{a} / d z=0.40^{\circ} \mathrm{C} / \mathrm{km}$. The misfit depends strongly on $T_{P}$ for the four oceanic and tectonically

498 active regions $(\mathrm{A}, \mathrm{B}, \mathrm{C}, \mathrm{Q})$, with well-defined minima at $T_{P}=1300^{\circ} \mathrm{C}$ for regions $\mathrm{A}$ and $\mathrm{B}$ and

$499 T_{P}=1250^{\circ} \mathrm{C}$ for regions $\mathrm{C}$ and $\mathrm{Q}$. The minimum misfit for the stable continents $(\mathrm{P}, \mathrm{S})$ occurs at

$500 T_{P}=1200^{\circ} \mathrm{C}$, although differences in the misfit calculated for $T_{P} \leq 1250^{\circ} \mathrm{C}$ are slight. In all

501 cases, the best-fitting intersection depth increases with $T_{P}$ (Fig. 6b), as expected: a thicker

502 TBL creates overall colder conditions in the uppermost mantle, which is necessary to

503 balance the overall higher temperatures produced when a hotter adiabat is used. If $d=10$

$504 \mathrm{~mm}$ instead of $1 \mathrm{~mm}$, the best-fitting $T_{P}$ values increase by $150-200^{\circ} \mathrm{C}$ relative to their values

505 at $d=1 \mathrm{~mm}$, but the best-fitting intersection depths are mostly unchanged. If

$506 d T_{a} / d z=0.25^{\circ} \mathrm{C} / \mathrm{km}$ or $0.55^{\circ} \mathrm{C} / \mathrm{km}$ instead of $0.40^{\circ} \mathrm{C} / \mathrm{km}$, the best-fitting $T_{P}$ values change by

$507 \leq 50^{\circ} \mathrm{C}$ and the best-fitting intersection depths change by $\leq 15 \mathrm{~km}$. Figs. $6 \mathrm{c}, \mathrm{d}$ show that

508 modeling the GTR1 values as simple TBLs yields Rayleigh wave attenuation values that are

509 highly similar to the observed values and can reduce the variance in the MMM16 amplitude

510 data set almost as well as the GTR1 values themselves except for period=200 s, presumably

511 because these deep-sampling, long-period Rayleigh waves are mostly sensing mantle

512 structure that is unrelated to the TBLs.

513 Fig. 7 summarizes the distribution of geotherms that provide a good fit to

514 attenuation values in the three oceanic and two cratonic regions in GTR1; we exclude

515 tectonically active continents from our analysis because the presence of partial melt in the 
516 mantle, for example in the Basin and Range (Plank and Forsyth, 2016) and Ethiopia (Bastow

517 et al., 2008), would violate the assumption that temperature variations are controlling

518 attenuation. For each region, acceptable geotherms are identified as those whose misfit

519 between observed and predicted attenuation, summed over the six periods, is less than the

520 summed misfit calculated using the error bars in Fig. 6c. The geotherms that fit the

521 attenuation constraints from the oceanic regions agree reasonably well with predictions

522 from the half-space-cooling model, with slightly thicker TBLs than the half-space-cooling

523 model due to the fact that our simplified geotherms overpredict attenuation under hot

524 conditions (Fig. S7) and thus the observed attenuation values will be mapped into slightly

525 colder temperatures. The range of geotherms that satisfy the attenuation constraints for the

526 GTR1 cratonic regions (Fig. $7 \mathrm{~b}$ ) have $T_{P}$ values between $1100^{\circ} \mathrm{C}$ and $1300^{\circ} \mathrm{C}$ and intersection

527 depths of $130-165 \mathrm{~km}$ for region $\mathrm{P}$ and $165-295 \mathrm{~km}$ for region $\mathrm{S}$ when $d=1 \mathrm{~mm}$. With this

528 grain size, the geotherms for regions $\mathrm{P}$ and $\mathrm{S}$ overlap with the temperature and pressure

529 conditions estimated from mantle xenoliths (Lee et al., 2011) with the exception of those

530 samples from depths $>175 \mathrm{~km}$. When $d=10 \mathrm{~mm}$, the best-fitting geotherms have similar

531 intersection depths and higher $T_{P}$ values $\left(1300^{\circ}-1450^{\circ} \mathrm{C}\right)$ than for $d=1 \mathrm{~mm}$; with the higher

$532 T_{P}$ values obtained using the larger grain size even the xenoliths from depths $>175 \mathrm{~km}$ fall

533 within the temperature fields estimated for regions P and S. Realistic cratonic geotherms

534 that incorporate radiogenic heat production in the crust and mantle (e.g., Rudnick et al.,

535 1998) agree well with the temperature fields, using $T_{P}=1300^{\circ} \mathrm{C}$ and average crustal heat 536 production $=0.65 \mu \mathrm{W} / \mathrm{m}^{3}$ and $0.75 \mu \mathrm{W} / \mathrm{m}^{3}$ when $d=1 \mathrm{~mm}$. 

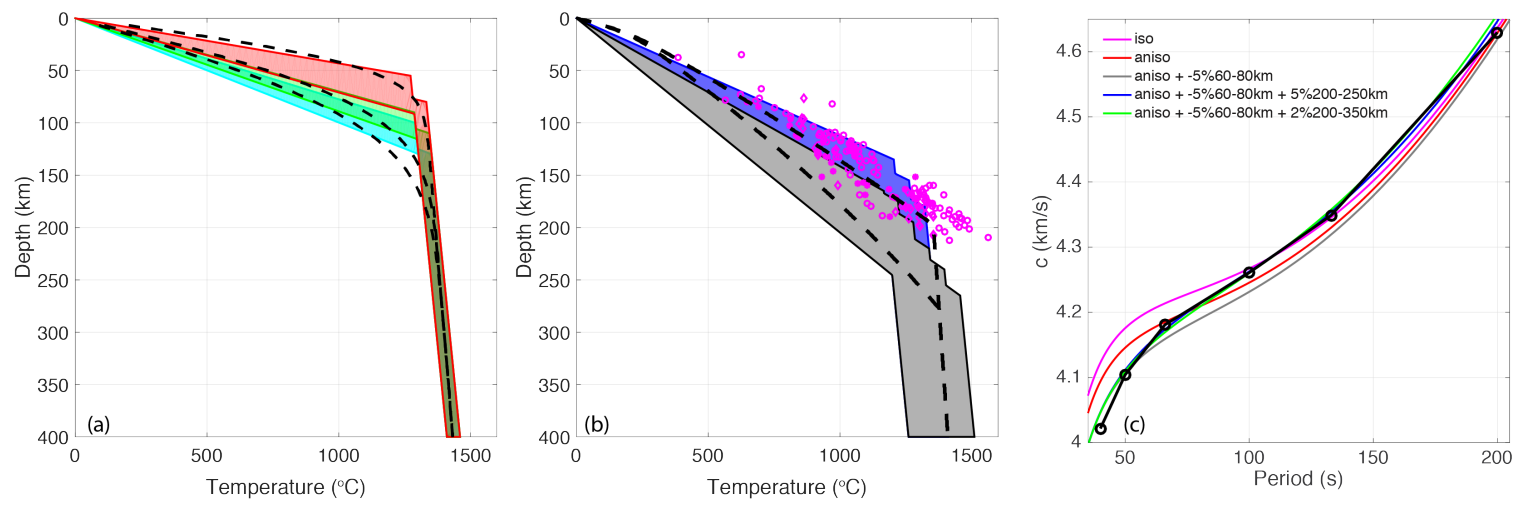

538 Figure 7. (a) Distribution of best-fitting geotherms for GTR1 oceanic regions: A (red), B (green), and

539 C (cyan). Dashed black lines show geotherms predicted by the half-space-cooling model with ages of

54025 Myr, 85 Myr, and 125 Myr. (b) Distribution of best-fitting geotherms for GTR1 cratonic regions: P

541 (blue) and S (grey). Dashed black lines show steady-state geotherms (Rudnick et al., 1998) calculated

542 with surface heat flow $=41 \mathrm{~mW} / \mathrm{m}^{2}$ and radiogenic heat production $=0.02 \mu \mathrm{W} / \mathrm{m}^{3}$ in the lithospheric

543 mantle and $=0.65 \mu \mathrm{W} / \mathrm{m}^{3}$ (shallower curve) and $0.75 \mu \mathrm{W} / \mathrm{m}^{3}$ (deeper curve) in the crust. Magenta

544 symbols show constraints from xenolith thermobarometry in the Slave craton, South Africa, and

545 Siberia (Lee et al., 2011). (c) Comparison of observed (black) and predicted phase velocity for GTR1

546 region S. Predicted values are obtained by converting the conductive geotherm for region $\mathrm{S}$ in (b)

547 into seismic velocity with different assumptions. All predictions have a 39-km continental crust and

$548 d=1 \mathrm{~mm}$. Magenta: isotropic velocity. Red: $\mathrm{V}_{\mathrm{SH}}-\mathrm{V}_{\mathrm{Sv}}=0.15 \mathrm{~km} / \mathrm{s}$ at depths $39-200 \mathrm{~km}$. Grey: As for red,

549 with the addition of a low-velocity zone from 60-80 km. Blue: As for grey, with the addition of a

550 strong high-velocity zone from 200-250 km. Green: As for grey, with the addition of a weak high-

551 velocity zone from $200-350 \mathrm{~km}$.

We next extend this approach to the global attenuation maps, which are expanded in

554 spherical harmonics to degree 16 (Fig. 4). We use the maps derived from the MMM16

555 amplitude data set at the same six periods that are used for the GTR1 analysis and calculate

556 the misfit between the observed and predicted attenuation values in each $1^{\circ} \times 1^{\circ}$ grid cell.

557 Fig. 8a shows the best-fitting intersection depth in grid cells for which our approach is most

558 appropriate: those that are characterized by Precambrian continental crust (Fig. 5a) in

559 CRUST1.0 and for which the minimum misfit is $<0.005$, a quality criterion determined from

560 the GTR1 analysis described above. For crustal rocks that are Early-Mid Proterozoic and

561 older in age the distribution of TBL thicknesses determined from these attenuation maps is 
562 very similar, with mean intersection depth $=180-190 \mathrm{~km}$. The TBL is considerably thinner

563 for regions containing Late Proterozoic crustal rocks (130 km) as well as all younger

564 continental regions $(120 \mathrm{~km})$, although as mentioned earlier our approach is likely not

565 appropriate for areas that may contain melt. From the distributions of best-fitting

566 geotherms in Fig. 7b, we calculate the standard deviation of intersection depths, which is 20

$567 \mathrm{~km}$ for region $\mathrm{P}$ and $33 \mathrm{~km}$ for region S. Thus, $30 \mathrm{~km}$ is a reasonable uncertainty on the TBL

568 values in Fig. 8a.
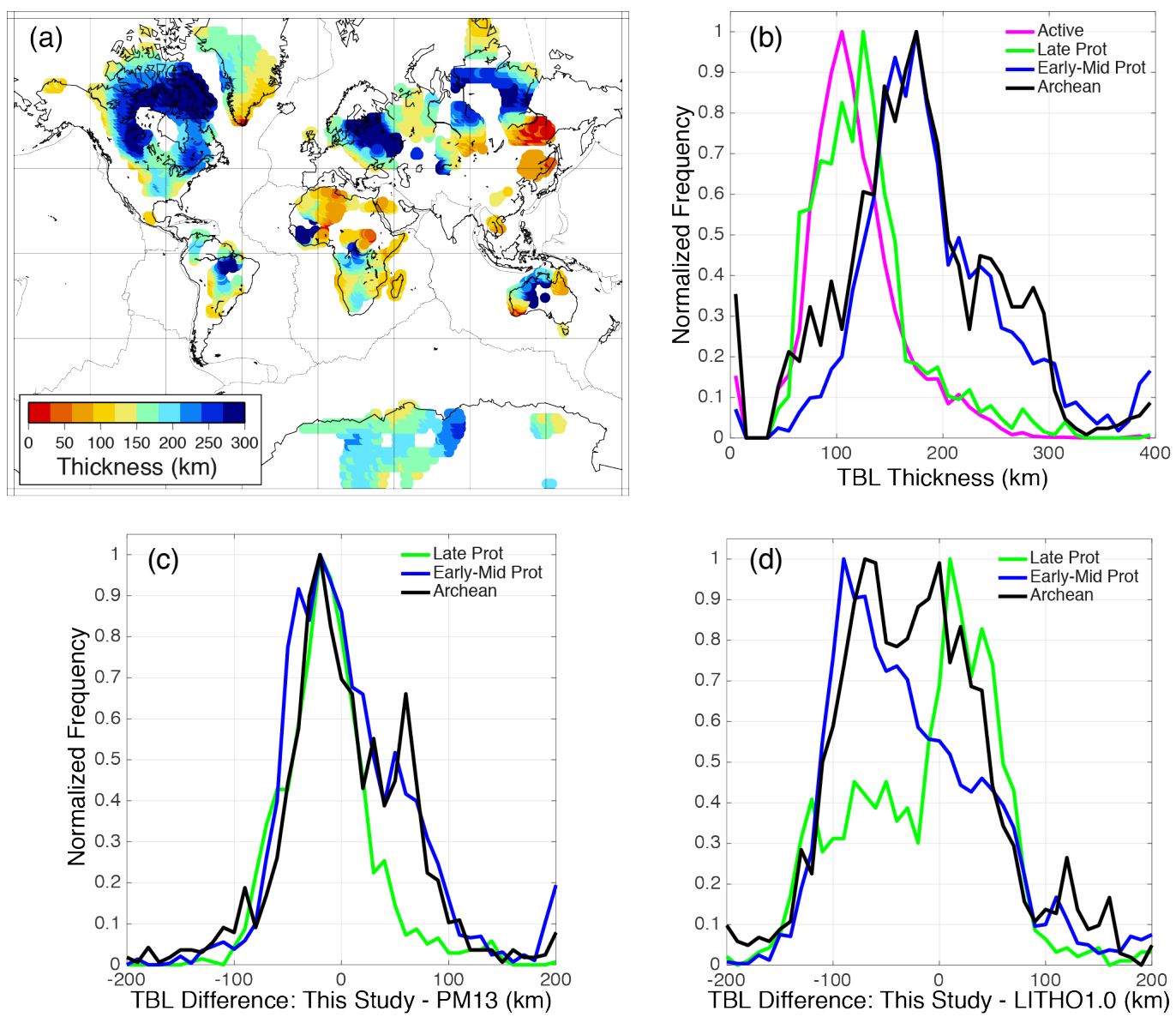

570 Figure 8. (a) Best-fitting intersection depth in pixels characterized by Precambrian crust and 571 minimum misfit $<0.005$. $d=1 \mathrm{~mm}$. (b) Distribution of intersection depths for continental crust of 572 different ages. "Active" describes crust younger than Precambrian. (c) Distribution of differences in 573 lithospheric thickness between this study and PM13. (d) Distribution of differences in lithospheric 574 thickness between this study and LITH01.0. 


\section{Discussion}

Estimating the thickness of the lithosphere from seismological constraints is not

578 straightforward. Since the lithosphere is a layer defined by its rheology, the seismological

579 constraints can serve only as a proxy, and in order to use them it is necessary to make

580 assumptions about how the rheological properties will manifest as seismological properties.

581 Commonly used approaches include the magnitude of and depth variations in absolute

582 shear velocity (e.g., Priestley and McKenzie, 2013), the strength and orientation of seismic

583 anisotropy (e.g., Yuan and Romanowicz, 2010), and receiver functions (e.g., Rychert et al.,

584 2005). While recent results support the idea that receiver functions can detect the

585 lithosphere-asthenosphere boundary (LAB) in continental areas where partial melt at the

586 LAB enhances the impedance contrast (Hansen et al., 2015), LAB detection with receiver

587 functions is less common and more controversial in cratonic settings (e.g., Abt et al., 2010;

588 Foster et al., 2014); scattering interfaces with a negative velocity gradient with depth are

589 typically interpreted as mid-lithospheric discontinuities in those areas. Shear velocities

590 determined from surface waves provide excellent vertical resolution in the uppermost

591 mantle; however, several studies have demonstrated that it is difficult to satisfy

592 observations of phase velocity in cratons given realistic mantle geotherms and a uniform

593 peridotite composition (Bruneton et al., 2004; Lebedev et al., 2009; Pedersen et al., 2009;

594 Hirsch et al., 2015). Here, we have used Rayleigh wave attenuation to estimate lithospheric

595 thickness by assuming that the lithosphere is defined as the thermal boundary layer across

596 which heat transfer occurs by conduction. Since our approach works best in cratonic areas,

597 our estimates of lithospheric thickness (Fig. 8a) are complementary to the LAB constraints

598 in magmatic/orogenic areas that are provided by receiver functions. Furthermore, the use

599 of attenuation instead of velocity avoids the need to make assumptions about mantle 
600 composition and seismic anisotropy. Below we compare our results to other global studies

601 of lithospheric thickness and discuss implications for shear-velocity structure.

602

\section{$603 \quad 6.1$ Comparison with Other Studies}

604 We compare our estimates of lithospheric thickness in cratonic areas to two global 605 studies. Priestley and McKenzie (2013; hereinafter PM13) estimated temperature profiles

606 from their global vertically polarized shear velocity ( $\left.\mathrm{V}_{\mathrm{sv}}\right)$ model in addition to constraints

607 from oceanic thermal models, garnet peridotite nodules, global shear attenuation, and 608 viscosity. They chose the base of the lithosphere based on the depth at which temperature 609 corresponds to a potential temperature of $1315^{\circ} \mathrm{C}$. The LITH01.0 model of Pasyanos et al.

610 (2014) consists of ten layers within which the density and seismic properties are constant

611 with depth; the lithospheric mantle is represented by a single layer. The thickness of the 612 layers and their properties are allowed to vary geographically in order to satisfy constraints 613 provided by Rayleigh and Love wave group- and phase-velocity maps.

614 Agreement between our results and PM13 is reasonably good (Fig. 8c). On average 615 our estimates of lithospheric thickness are smaller by $20 \mathrm{~km}$ than PM13, and the two sets of 616 values differ by $<50 \mathrm{~km}$ for $76 \%, 66 \%$, and $64 \%$ of the Late Proterozoic, Early-Mid 617 Proterozoic, and Archean crust, respectively. The histogram of differences contains a 618 secondary peak at 50-60 km for the Early-Mid Proterozoic and Archean crust. The fact that 619 the geographic locations corresponding to this peak are distributed across all continents 620 suggests that shear velocity may systemically underestimate lithospheric thickness in 621 certain areas of very old continental lithosphere. Agreement with LITHO1.0 is weaker, 622 especially for the Early-Mid Proterozoic and Archean crust (Fig. 8d); in those areas our 623 lithosphere is thinner by $70-90 \mathrm{~km}$ on average. The fact that we find better agreement with 624 PM13 than LITH01.0 is not surprising given the nature of the different approaches used. 
625 Although PM13 rely mostly on shear velocity instead of attenuation and use a different

626 criterion to identify the base of the lithosphere, their strategy of trying to map seismic

627 properties into realistic TBL-type geotherms is similar to ours. On the other hand, treating

628 the lithospheric mantle as a single layer of constant velocity and trying to simultaneously fit

629 Rayleigh and Love wave velocities with isotropic shear-wave speed may result in larger

630 uncertainties in the LAB depths in Pasyanos et al. (2014).

631

\section{$632 \quad 6.2$ Implications for Shear-Velocity Structure}

633 The temperature profiles that best fit the attenuation constraints in cratonic areas

634 (Fig. 7b) struggle to also provide a satisfactory fit to the phase-velocity observations in

635 these areas. Earlier studies have reached similar conclusions. Shear-velocity profiles lacking

636 a low-velocity zone and characterized by flat or positive velocity gradients with depth have

637 been observed in the central Baltic Shield (Bruneton et al., 2004; Zhu and Tromp, 2013), the

638 East European craton (Zhu and Tromp, 2013), central Australia (Fishwick and Reading,

639 2008), and the Slave, Yilgarn, and South-Central Finland cratons (Pedersen et al., 2009).

640 For comparison to the phase-velocity observations, the conductive geotherm

641 corresponding to surface heat flow $=41 \mathrm{~mW} / \mathrm{m}^{2}$ and crustal heat production $=0.75 \mu \mathrm{W} / \mathrm{m}^{3}$

642 (deeper black dashed curve in Fig. 7b) is used rather than our simplified temperature

643 profiles. Fig. 7c shows the comparison of observed and predicted phase velocity for GTR1

644 region $\mathrm{S}$ for scenarios with isotropy and radial anisotropy $\left(\mathrm{V}_{S H}-\mathrm{V}_{S V}=0.15 \mathrm{~km} / \mathrm{s}\right.$, where $\mathrm{V}_{S H}$ is

645 the horizontally polarized shear velocity; Gaherty and Jordan, 1995; Gung et al., 2003; Yuan

646 and Romanowicz, 2010) from the Moho to $200 \mathrm{~km}$; the former predicts velocities that are

647 too high at short periods, and the latter predicts velocities that are slightly high at short

648 periods and too low at long periods. We experiment with what adjustments to the mantle

649 velocities are necessary to match the observations. Reducing seismic velocities by $5 \%$ in the 
650 depth range $60-80 \mathrm{~km}$ solves the problem at short periods. While the broad depth

651 sensitivity of Rayleigh waves permits a range of velocity structures that can produce the low

652 velocities necessary, our tests have shown that the velocity reduction must begin no deeper

653 than $70 \mathrm{~km}$ in order to match the 40 -s phase velocities. The magnitude and depth extent of

654 the low-velocity layer in the shallow mantle is consistent with observations of a mid-

655 lithospheric discontinuity in receiver functions (e.g., Hansen et al., 2015; Selway et al.,

656 2015). Mechanisms proposed to explain this velocity reduction include the presence of

657 minerals amphibole (Selway et al., 2015) and/or phlogopite (Hansen et al., 2015).

658 Matching the high velocities at long periods requires elevating $\mathrm{V}_{\mathrm{SV}}$ above its

659 geotherm-predicted value at depths $>200 \mathrm{~km}$. The non-uniqueness of this high-velocity

660 layer is illustrated in Fig. 7c: a 5\% increase distributed over $50 \mathrm{~km}$ and a $2 \%$ increase

661 distributed over $150 \mathrm{~km}$ both provide reasonable predictions of Rayleigh wave phase

662 velocity. Although longer-period and/or higher-mode Rayleigh waves are needed to resolve

663 the maximum depth extent of this feature, the observed phase velocities can more tightly

664 constrain the shallow extent. Putting the top of the high-velocity layer at $150 \mathrm{~km}$ or $250 \mathrm{~km}$

665 results in phase-velocity predictions that are too high and too low, respectively, for periods

$66650-100$ s. A velocity increase at $\sim 200 \mathrm{~km}$ beneath continents was suggested by Lehmann

667 (1959), and the Lehmann discontinuity has been the focus of numerous subsequent studies

668 (e.g., Revenaugh and Jordan, 1991; Gaherty and Jordan, 1995; Gu et al., 2001), many of

669 which favor seismic anisotropy as an explanation. In this study we cannot draw any

670 conclusions about anisotropy, since the Rayleigh wave phase velocities constrain only $\mathrm{V}_{\mathrm{SV}}$.

671 For the anisotropic models shown in Fig. 7c, the temperature-predicted shear velocity is

672 assigned to isotropic (Voigt average) shear velocity with the assumption that $\mathrm{V}_{\mathrm{SH}}-\mathrm{V}_{\mathrm{SV}}=0.15$

$673 \mathrm{~km} / \mathrm{s}$ from the Moho to 200-km depth. Fig. 7c makes clear that the slight increase in $\mathrm{V}_{\mathrm{Sv}}$ that

674 results from terminating this radial anisotropy at $200 \mathrm{~km}$ is too small to satisfy the 
675 observations (Fig. 7c); furthermore, allowing $\mathrm{V}_{\mathrm{SH}}>\mathrm{V}_{\mathrm{SV}}$ to persist to greater depths only 676 exacerbates the mismatch between observations and predictions. While this result would 677 seem to indicate that the required velocity increase is not entirely anisotropic in nature 678 (Vinnik et al., 2005), further analysis that incorporates observations sensitive to $V_{S H}$ is 679 required in order for definite conclusions to be drawn.

680

\section{$681 \quad 7.0$ Conclusions}

682 Three independent data sets of Rayleigh wave amplitudes are analyzed to assess the 683 origin of differences between global models of attenuation. A fourth data set of synthetic 684 amplitudes, generated using spectral-element simulations with 3-D elastic and 1-D anelastic 685 Earth models, serves as a benchmark for how focusing and scattering effects can introduce 686 bias into attenuation values and guides our treatment of real amplitude data. The fact that 687 inversions of the synthetic amplitudes can resolve the input structures well (Fig. 2) and 688 produce regionalized attenuation values very different from those found with real data (Fig. 689 3) serves as strong evidence that dissipative mechanisms, rather than scattering effects, are 690 responsible for observed seismic attenuation, at least in the period band 40-200 s. 691 Furthermore, while the synthetic amplitudes have been used to demonstrate that ERT and 692 FFT better describe focusing effects at short and long periods (Fig. 1), respectively, the 693 analysis of these data has also made clear that the effect on attenuation models of 694 differences between the various focusing treatments is much smaller than the effect of 695 removing versus not removing focusing effects.

696 The three amplitude data sets are highly consistent with each other, and any 697 differences between the measurement algorithms have a negligible effect on the attenuation 698 structure. Differences in the treatment of focusing effects degrade the level of agreement 699 between the degree-16 maps only slightly. Differences in the path coverage are the single 
700 biggest factor contributing to discrepancies between the maps, and in fact removing

701 focusing effects from the amplitudes helps to counteract the detrimental impact of variable 702 path coverage (Fig. 5b).

703 The regionalized attenuation and phase-velocity values are anti-correlated with 704 each other (Figs. 3c,d), and the dependence on tectonic region disappears by $200 \mathrm{~s}$ for all 705 regions but the stable continents. While the short-period phase velocities are strongly

706 influenced by crustal structure, the short-period attenuation values are not, which is an 707 advantage for constraining mantle attenuation structure. The degree-16 attenuation maps 708 (Fig. 4) achieve a higher resolution than earlier global studies and clearly image very low 709 attenuation associated with specific continental cratons. The frequency-dependent 710 attenuation values at periods $<200 \mathrm{~s}$ are well fit by modeling the thermal structure of the

711 cratonic upper mantle as a simple boundary layer, and the field of best-fitting geotherms

712 overlaps with temperature constraints from mantle xenoliths (Figs. 6-7). By equating the

713 boundary layer with the lithosphere in cratonic areas we show that the distribution of

714 lithospheric thicknesses is peaked at $190 \mathrm{~km}$ for crust older than the Mid-Proterozoic, with 715 a secondary peak at $250-300 \mathrm{~km}$ (Fig. 8). The geotherms that satisfy the attenuation and 716 xenolith constraints, however, cannot match the observed cratonic phase velocities. A 5\%

717 velocity reduction at depths $60-80 \mathrm{~km}$ can remove the discrepancy at short periods and is

718 consistent with receiver-function observations of a mid-lithospheric discontinuity in

719 cratons. A velocity increase around 200-km depth is needed to satisfy the long-period phase

720 velocities and may be related to the Lehmann discontinuity observed intermittently in

721 continental areas.

722

723 Acknowledgements

724 This work was funded by National Science Foundation award EAR-144432 to C.A.D. 
726 Table 1. Summary of the four data sets of fundamental-mode Rayleigh wave amplitudes.

727 The final column reports the approximate theory and phase-velocity maps with which

728 focusing effects have been pre-calculated and used in this study.

\begin{tabular}{|l|l|l|l|}
\hline Data Set \& Reference & Periods (s) & Number of Paths & Focusing Corrections \\
\hline DED08 (Dalton et al., & $50,75,100,125$ & $215,345-299,138$ & GCRA; maps of \\
BDR16 (Bao et al., & 50,100 & $390,360-393,464$ & ERT, FFT, GCRA; \\
2016) & & & maps of BDR16 \\
\hline $\begin{array}{l}\text { MMM16 (Ma et al., } \\
\text { 2016) }\end{array}$ & $40,50,66,100,133$, & $137,548-251,030$ & FFT; maps of \\
\hline SPECFEM (Dalton et & $50,75,125$ & & MMM16 \\
al., 2014) & & 4,749 & ERT, FFT, GCRA; \\
\hline
\end{tabular}

729

730 Table 2. Pure-path Rayleigh wave attenuation values (1/Q) for GTR1 (Fig. 3c).

\begin{tabular}{|c|c|c|c|c|c|c|}
\hline & $\mathrm{A}$ & $\mathrm{B}$ & $\mathrm{C}$ & $\mathrm{P}$ & $\mathrm{Q}$ & $\mathrm{S}$ \\
\hline $40 \mathrm{~s}$ & 0.0085 & 0.0056 & 0.0048 & 0.0022 & 0.0058 & 0.0011 \\
\hline $50 \mathrm{~s}$ & 0.0097 & 0.0073 & 0.0062 & 0.0031 & 0.0075 & 0.0018 \\
\hline $66 \mathrm{~s}$ & 0.0113 & 0.0090 & 0.0077 & 0.0044 & 0.0088 & 0.0030 \\
\hline $100 \mathrm{~s}$ & 0.0112 & 0.0100 & 0.0085 & 0.0057 & 0.0092 & 0.0049 \\
\hline $133 \mathrm{~s}$ & 0.0099 & 0.0090 & 0.0085 & 0.0058 & 0.0081 & 0.0052 \\
\hline $200 \mathrm{~s}$ & 0.0064 & 0.0067 & 0.0062 & 0.0046 & 0.0059 & 0.0045 \\
\hline
\end{tabular}

731

732 


\section{References}

735

736 Abers, G.A., K.M. Fischer, G. Hirth, D.A. Wiens, T. Plank, B.K. Holtzman, C. McCarthy, and E. 737 Gazel, Reconciling mantle attenuation-temperature relationships from seismology, petrology, and laboratory measurements, Geochem. Geophys. Geosyst., 15,

740 Abt, D.L., K.M. Fischer, S.W. French, H.A. Ford, H. Yuan, and B. Romanowicz, North American 741 lithospheric discontinuity structure imaged by Ps and Sp receiver functions, J. 742 Geophys. Res., 115, 1978-2012, 2010.

743 Artemieva, I.M., The continental lithosphere: Reconciling thermal, seismic, and petrologic $744 \quad$ data, Lithos, 109, 23-46, 2009.

745 Bao, X., C.A. Dalton, and J. Ritsema, Effects of elastic focusing on global models of Rayleigh 746 wave attenuation, Geophys. J. Int., doi:10.1093/gji/ggw332, 2016.

747 Bastow, I.D., A.A. Nyblade, G.W. Stuart, T.O. Rooney, and M.H. Benoit, Upper mantle seismic 748 structure beneath the Ethiopian hot spot: Rifting at the edge of the African low749 velocity anomaly, Geochem. Geophys. Geosys., 9, doi:10.1029/2008GC002107, 2008.

750 Bruneton, M., H. A. Pedersen, P. Vacher, I. T. Kukkonen, N. T. Arndt, S. Funke, W. Friederich, 751 and V. Farra, Layered lithospheric mantle in the central Baltic shield from surface 752 waves and xenolith analysis, Earth Planet. Sci. Lett., 226, 41-52, 753 doi:10.1016/j.epsl.2004.07.034, 2004.

754 Dalton, C.A., and G. Ekström, Global models of surface-wave attenuation, J. Geophys. Res., 755 111, B05317, doi:10.1029/2005JB003997, 2006.

756 Dalton, C.A., G. Ekström, and A.M. Dziewonski, The global attenuation structure of the upper 757 mantle, J. Geophys. Res., 113, B09303, doi:10.1029/2007JB005429, 2008. 
758 Dalton, C.A., G. Ekström, and A.M. Dziewonski, Global seismological shear velocity and 759 attenuation: A comparison with experimental observations, Earth Planet. Sci. Lett., $760 \quad$ 284, 65-75, doi:10.1016/j.epsl.2009.04.009, 2009.

761 Dalton, C.A., V. Hjörleifsdóttir, and G. Ekström, A comparison of approaches to the prediction 762 of surface-wave amplitude, Geophys. J. Int., doi:10.1093/gji/ggt365, 2014.

763 Durek, J.J., and G. Ekström, A radial model of anelasticity consistent with long-period surface 764 wave attenuation, Bull. Seism. Soc. Am., 86, 144-158, 1996.

765 Dziewonski, A.M., and D.L. Anderson, Preliminary reference Earth model, Phys. Earth Planet. $766 \quad$ Inter., 25, 297-356, 1981.

767 Dziewonski, A.M., T.A. Chou, and J.H. Woodhouse, Determination of earthquake source 768 parameters from waveform data for studies of global and regional seismicity. $J$. 769 Geophys. Res., 86, doi: 10.1029/JB086iB04p02825, 2825-2852, 1981.

770 Ekström, G., A global model of Love and Rayleigh surface wave dispersion and anisotropy, 771 772 25-250 s, Geophys. J. Int., 187, 1668-1686, doi:10.1111/j.1365-246X.2011.05225.x,

773 Ekström, G., J. Tromp, and E.W.F. Larson, Measurements and global models of surface wave $774 \quad$ propagation, J. Geophys. Res., 102, 8137-8157, 1997.

775 Ekström, G., C.A. Dalton, and M. Nettles, Observations of time-dependent errors in the long776 period instrument gain at global seismic stations, Seismol. Res. Lett., 77, 12-22, 2006.

777 Ekström, G., M. Nettles, and A.M. Dziewonski, The global CMT project 2004-2010: Centroid778 moment tensors for 13,017 earthquakes, Phys. Earth Planet. Inter., 200-201, 1-9, 779 doi:10.1016/j.pepi.2012.04.002, 2012.

780 Ferreira, A.M., and J.H. Woodhouse, Source, path and receiver effects on seismic surface 781 waves, Geophys. J. Int., 168, 109-132, doi:10.1111/j.1365-246X.2006.03092.x, 2006.

782 Fishwick, S., and A. M. Reading, Anomalous lithosphere beneath the Proterozoic of western 
and central Australia: A record of continental collision and intraplate deformation?, Precambrian Res., 166, 111-121, doi:10.1016/j.precamres.2007.04.026, 2008.

785 Forsyth, D.W., Geophysical constraints on mantle flow and melt generation beneath mid786 ocean ridges. Mantle flow and melt generation at mid-ocean ridges. AGU Geophysical Monograph. 71, 1-65, 1992.

Foster, K., K. Dueker, B. Schmandt, and H. Yuan, A sharp cratonic lithosphere-asthenosphere boundary beneath the American Midwest and its relation to mantle flow, Earth Planet. Sci. Lett., 402, 82-89, 2014.

791 Gaherty, J.B., and T.H. Jordan, Lehmann discontinuity as the base of an anisotropic layer

Goes, S., and S. van der Lee, Thermal structure of the North American uppermost mantle beneath continents, Science, 268, 1468-1471, 1995. inferred from seismic tomography, J. Geophys. Res., 107, doi:10.1029/2000JB000049, 2002.

Goes, S., R. Govers, and P. Vacher, Shallow mantle temperature under Europe from P and S wave tomography, J. Geophys. Res., 105, 11,153-11,169, doi:10.1029/1999JP900300, 7982000.

799 Gu, Y.J., A.M. Dziewonski, and G. Ekström, Preferential detection of the Lehmann 800 discontinuity beneath continents, Geophys. Res. Lett., 28, 4655-4658, 2001.

801 Gung, Y.C., M. Panning, and B. Romanowicz, Anisotropy and lithospheric thickness, Nature, $802 \quad 422,707-711,2003$.

803 Hansen, S.M., K. Dueker, and B. Schandt, Thermal classification of lithospheric 804 discontinuities beneath USArray, Earth Planet. Sci. Lett., 431, 36-47, 2015.

805 Hirsch, A.C., C.A. Dalton, and J. Ritsema, Constraints on shear velocity in the cratonic upper 806 mantle from Rayleigh wave phase velocity, Geochem. Geophys. Geosys., 16, 807 doi:10.1002/2015GC006066, 2015. 
808 Jackson, I., and U.H. Faul, Grainsize-sensitive viscoelastic relaxation in olivine: Towards a 809 robust laboratory-based model for seismological application, Phys. Earth. Planet. $810 \quad$ Inter., 183, 151-163, 2010.

811 Jackson, I., U.H. Faul, J.D. Fitz Gerald, and B.H. Tan, Shear wave attenuation and dispersion in 812 melt-bearing olivine polycrystals: 1. Specimen fabrication and mechanical testing, J. 813 Geophys. Res., 109, doi:10.1029/2003JB002406, 2004. .

814 Jordan, T.H., Global tectonic regionalization for seismological data analysis, Bull. Seismol. $815 \quad$ Soc. Am., 71, 1131-1141, 1981.

816 Karato, S., Mapping water content in the upper mantle, Inside the Subduction Factory, AGU 817 Geophys. Monogr., 138, 135-152, 2003.

818 Komatitsch, D., and J. Tromp, Spectral-element simulations of global seismic wave 819 propagation-I. Validation, Geophys. J. Int., 149, 390-412, doi: 10.1046/j.1365$820 \quad$ 246X.2002.01653.x, 2002a.

821 Komatitsch, D., and J. Tromp, Spectral-element simulations of global seismic wave 822 propagation-II. 3-D models, oceans, rotation, and self-gravitation, Geophys. J. Int., 823 150, 303-318, doi: 10.1046/j.1365-246X.2002.01716.x, 2002b.

824 Larson, E.W.F., J. Tromp, and G. Ekström, Effects of slight anisotropy on surface waves, 825 Geophys. J. Int., 132, 654-666, 1998.

826 Laske, G., G. Masters, Z. Ma, and M. Pasyanos, Update on CRUST1.0-A 1-degree global 827 model of Earth's crust, Geophys. Res. Abstr., 15, Abstract EGU2013-2658, 2013.

828 Lebedev, S., J. Boonen, and J. Trampert, Seismic structure of Precambrian lithosphere: New 829 constraints from broad-band surface-wave dispersion, Lithos, 109, 91-111, 2009.

830 Lee, C.-T. A., P. Luffi, and E. J. Chin, Building and destroying continental mantle, Annu. Rev. 831 Earth Planet. Sci. Lett., 39, 59-90, doi:10.1146/annurev-earth-040610-133505, $832 \quad 2011$. 
833 Lehmann, I., Velocities of longitudinal waves in the upper part of the Earth's mantle, Ann. 834 Geophys., 15, 93-118, 1959.

835 Ma., Z., G. Masters, G. Laske, and M.E. Pasyanos, A comprehensive dispersion model of 836 surface wave phase and group velocity for the globe, Geophys. J. Int., 199, 837 doi:10.1093/gji/ggu246, 2014.

838 Ma, Z., G. Masters, and N. Mancinelli, Two-dimensional global Rayleigh wave attenuation 839 model by accounting for finite-frequency focusing and defocusing effect, Geophys. J. $840 \quad$ Int., 204, 631-649, 2016.

841 McCarthy, C., and Y. Takei, Anelasticity and viscosity of partially molten rock analogue: 842 toward seismic detection of small quantities of melt, Geophys. Res. Lett., 38, $843 \quad$ 10.1029/2011GL048776, 2011.

844 McCarthy, C., Y. Takei, and T. Hiraga, Experimental study of attenuation and dispersion over 845 a broad frequency range: 2 . The universal scaling of polycrystalline materials, $J$. 846 Geophys. Res., 116, doi:10.1029/2011JB008384, 2011.

847 Meschede, M., and B. Romanowicz, Non-stationary spherical random media and their effect 848 on long-period mantle waves, Geophys. J. Int., 203, 1605-1625, 2015.

849 Müller, R.D., M. Sdrolias, C. Gaina, and W.R. Roest, Age, spreading rates and spreading 850 symmetry of the world's ocean crust, Geochem. Geophys. Geosyst., 9, Q04006, 851 doi:10.1029/2007GC001743, 2008.

852 Pasyanos, M.E., T.G. Masters, G. Laske, and Z. Ma, LITH01.0: An updated crust and 853 lithospheric model of the Earth, J. Geophys. Res., 119, 2153-2173, 854 doi:10.1002/2013JB010626, 2014.

855 Pedersen, H.A., S. Fishwick, and D.B. Snyder, A comparison of cratonic roots through 856 consistent analysis of seismic surface waves, Lithos, 109, 81-95, 857 doi:10.1016/j.lithos.2008.09.016, 2009. 
858 Plank, T., and D.W. Forsyth, Thermal structure and melting conditions in the mantle beneath

859 the Basin and Range province from seismology and petrology, Geochem. Geophys.

$860 \quad$ Geosyst., 17, 1312-1338, doi:10.1002/2015GC006205, 2016.

861 Priestley, K., and D. McKenzie, The relationship between shear wave velocity, temperature, 862 attenuation, and viscosity in the shallow part of the mantle, Earth Planet. Sci. Lett.,

864 Revenaugh, J., and T.H. Jordan, Mantle layering from ScS reverberations: 3. The upper 865 mantle, J. Geophys. Res., 96, 19781-19810, 1991.

866 Ricard, Y., S. Durand, J.-P. Montagner, and F. Chambat, Is there seismic attenuation in the 867 mantle?, Earth Planet. Sci. Lett., 388, 257-264, 2014.

868 Ritsema, J., A. Deuss, H.J. van Heijst, and J.H. Woodhouse, S40RTS: A degree-40 shear869 velocity model for the mantle from new Rayleigh wave dispersion, teleseismic travel 870 time and normal-mode splitting function measurements, Geophys. J. Int., 184, 1223871 1236, doi:10.1111/j.1365-246X.2010.04884.x, 2011.

872 Romanowicz, B., A global tomographic model of shear attenuation in the upper mantle, J. 873 Geophys. Res., 100, 12375-12394, 1995.

874 Romanowicz, B., and Y.C. Gung, Superplumes from the core-mantle boundary to the 875 lithosphere: implications for heat-flux, Science, 296, 513-516, 2002.

876 Rudnick, R. L., W. F. McDonough, and R. J. O'Connell, Thermal structure, thickness, and 877 composition of continental lithosphere, Chem. Geol., 145, 395-411, 1998.

878 Rychert, C.A., K.M. Fischer, and S. Rondenay, A sharp lithosphere-asthenosphere boundary 879 imaged beneath eastern North America, Nature, 436, 542-545, 2005.

880 Rychert, C.A., K.M. Fischer, G.A. Abers, T. Plank, E. Syracuse, J.M. Protti, V. Gonzalez, and W. 881 Strauch, Strong along-arc variations in attenuation in the mantle wedge beneath 
Costa Rica and Nicaragua, Geochem. Geophys. Geosyst., 9, Q10S10, 883 doi:10.1029/2008GC002040, 2008.

884 Selby, N.D., and J.H. Woodhouse, Controls on Rayleigh wave amplitudes: attenuation and 885 focusing, Geophys. J. Int., 142, 933-940, 2000.

886 Selway, K., H. Ford, and P. Kelemen, The seismic mid-lithospheric discontinuity, Earth 887 Planet. Sci. Lett., 414, 45-57, 2015.

888 van Heijst, H.J., and J.H. Woodhouse, Measuring surface-wave overtone phase velocities 889 using a mode branch stripping technique, Geophys. J. Int., 131, 209-230, 1997.

890 Vinnik, L., E. Kurnik, and V. Farra, Lehmann discontinuity beneath North America: No role 891 for seismic anisotropy, Geophys. Res. Lett., 32, doi:10.1029/2004GL022333, 2005.

892 Wang, Z., and F.A. Dahlen, JWKB surface-wave seismograms on a laterally heterogeneous 893 earth, Geophys. J. Int., 119, 381-401, 1994.

894 Wang, Z., and F.A. Dahlen, Validity of surface-wave ray theory on a laterally heterogeneous 895 earth, Geophys. J. Int., 123, 10.1111/j.1365-246X.1995.tb06888.x, 757-773, 1995.

896 Woodhouse, J.H., and Y.K. Wong, Amplitude, phase, and path anomalies of mantle waves, 897 Geophys. J. R. Astron. Soc., 87, 753-773, 1986.

898 Yang, Y., and D.W. Forsyth, Attenuation in the upper mantle beneath Southern California: 899 Physical state of the lithosphere and asthenosphere, J. Geophys. Res., 113, B033308, 900 doi:10.1029/2007JB005118, 2008.

901 Yang, Y., D.W. Forsyth, and D.S. Weeraratne, Seismic attenuation near the East Pacific Rise 902 and the origin of the low-velocity zone, Earth Planet. Sci. Lett., 258, 260-268, 903 doi:10.1016/j.epsl.2007.03.040, 2007.

904 Yuan, H., and B. Romanowicz, Lithospheric layering in the North American craton, Nature, 9054 466, doi:10.1038/nature09332, 1063-1069, 2010. 
906 Zhou, Y., F.A. Dahlen, and G. Nolet, Three-dimensional sensitivity kernels for surface wave 907 observables, Geophys. J. Int., 158, 142-168, doi:10.1111/j.1365-246X.2004.02324.x, 9082004.

909 Zhu, H., and J. Tromp, Mapping tectonic deformation in the crust and upper mantle beneath 910 Europe and the north Atlantic ocean, Science, 341, 871-875, 911 doi:10.1126/science.1241335, 2013.

912 Zhu, H., E. Bozdag, T.S. Duffy, and J. Tromp, Seismic attenuation beneath Europe and the 913 North Atlantic: Implications for water in the mantle, Earth Planet. Sci. Lett., 381, 1-

$914 \quad 11,2013$.

915

916

917

918 